\title{
An evaluation of adherence in patients with multiple sclerosis newly initiating treatment with a self-injectable or an oral disease-modifying drug
}

\author{
Michael Munsell' \\ Molly Frean' \\ Joseph Menzin' \\ Amy L Phillips ${ }^{2}$ \\ 'Boston Health Economics, Inc., \\ Waltham, MA, USA; ${ }^{2}$ Health \\ Economics \& Outcomes Research, \\ EMD Serono Inc., Rockland, MA, USA
}

Correspondence: Joseph Menzin Boston Health Economics, Inc., 20 Fox Road, Waltham, MA 0245I, USA

$\mathrm{Tel}+\mathrm{I} 78 \mid 2900808$

Fax + I 78I 2900029

Email jmenzin@bhei.com
This article was published in the following Dove Press journal:

Patient Preference and Adherence

30 December 2016

Number of times this article has been viewed

\begin{abstract}
Objective: As the multiple sclerosis (MS) disease-modifying drug (DMD) treatment options have expanded to include oral therapies, it is important to understand whether route of administration is associated with DMD adherence. The objective of this study was to compare adherence to DMDs in patients with MS newly initiating treatment with a self-injectable versus an oral DMD.
\end{abstract}

Methods: This retrospective database study used IMS Health Real World Data Adjudicated Claims - US data between July 1, 2010 and June 30, 2014. Adherence was measured by medication possession ratio (MPR), calculated as the total number of treated days divided by the total number of days from the first treated day until the end of 12-month follow-up. A binary measure representing adherence (MPR $\geq 0.8$ ) versus nonadherence (MPR $<0.8$ ) to therapy was used. Logistic regression evaluated the likelihood of adherence to index DMD type (self-injectable vs oral). Covariates included patient baseline characteristics (ie, age, sex, comorbidities) and index DMD type.

Results: The analysis included 7,207 self-injectable and 1,175 oral DMD-treated patients with MS. In unadjusted analyses, the proportion of patients adherent to therapy (MPR $\geq 0.8$ ) did not differ significantly between the self-injectable (54.1\%) and the oral DMD cohorts $(53.0 \%$; $P=0.5075$ ). After controlling for covariates, index DMD type was not a significant predictor of adherence (odds ratio [OR] 1.062; 95\% confidence interval [CI]: 0.937-1.202; $P=0.3473$ ). Higher likelihood of adherence was associated with male sex (OR 1.20; 95\% CI: $1.085-1.335 ; P=0.0005$ ) and age groups older than $18-34$ years (ORs 1.220-1.331; $P<0.01$ ). Depression was associated with a lower likelihood of adherence (OR 0.618; 95\% CI: $0.511-0.747 ; P<0.0001$ ).

Conclusion: Male sex and age older than 18-34 years were significantly associated with a higher likelihood of adherence, while depression was associated with a lower likelihood of adherence. Index DMD type, stratified by the route of administration (self-injectable vs oral DMD), was not a significant predictor of DMD adherence.

Keywords: multiple sclerosis, adherence, disease-modifying drugs, self-injectable, oral, mode of administration

\section{Introduction}

Multiple sclerosis (MS) is an inflammatory-mediated chronic neurodegenerative disease characterized by a range of symptoms including fatigue, impaired motor skills, blurred vision, bladder and bowel dysfunction, and cognitive impairment. ${ }^{1}$ More than 2.3 million people are affected by MS worldwide. ${ }^{1}$ The economic and humanistic burden of this chronic disease is substantial, particularly because patients with MS are affected at a young age, resulting in a greater loss of productivity and quality of life 
compared with other diseases. ${ }^{2}$ Although there is no cure for MS, effective strategies are available to treat exacerbations (relapses), modify the disease course, manage symptoms, and improve function. ${ }^{3}$ Along with the other essential components of comprehensive MS care, these treatments may help people manage their MS and enhance their comfort and quality of life. ${ }^{4}$

Disease-modifying drugs (DMDs) have been shown to be efficacious in reducing relapse frequency in MS; however, many patients experience barriers to DMD treatment adherence. Published rates of adherence to DMDs range from $28 \%$ to $88 \%{ }^{5-8}$ Patients who are adherent to DMDs have been shown to have a decreased risk of relapse, fewer emergency room visits, fewer severe relapses, fewer hospitalizations, fewer neuropsychological issues, lower costs, and increased quality of life, compared with nonadherent patients..$^{9-12}$

Adherence to therapy is rooted in a wealth of softer, often intangible, motivations that complicate its understanding and hinder its quantification. ${ }^{13} \mathrm{MS}$-specific disease characteristics that may be related to adherence are believed to include long periods of disease remission, lack of disease predictability, inadequate knowledge of the disease or its treatments, fear of needles, side effects of therapies, cognitive impairment, and low self-efficacy. ${ }^{14-16}$

In order to effectively treat patients with MS, it is important to understand the various factors that are associated with adherence to DMDs. An understanding of the predictive value of the factors associated with adherence in MS could contribute positively to the overall planning of MS disease management programs and improved patient outcomes. Many studies of varying design and methodology have evaluated factors associated with DMD adherence in MS..$^{5,9,17-47}$ Factors that have been shown to be associated with a statistically significant improvement in adherence to DMD treatment include older age, male sex, greater patient self-efficacy, reduced depression and anxiety, a positive relationship with the provider, less disability, and shorter duration of illness.

Self-injectable DMDs have historically been the most commonly used DMDs. In recent years, newer DMDs, including oral and infusion formulations, have been approved for the treatment of MS. To our knowledge, no existing studies in the published literature have examined the impact of route of administration on adherence to DMD therapy in MS. However, three studies comparing adherence of self-injectable versus oral DMDs have been presented at scientific conferences. ${ }^{48-50}$ The first study compared adherence and persistence across various dosing frequencies and routes of administration among patients with MS treated with DMDs. ${ }^{50}$ The authors found that adherence to oral daily, oral twice daily, subcutaneous (SC) three times weekly, and intramuscular weekly regimens was significantly higher than adherence to SC every other day or SC daily regimen. The second study sought to determine if adherence and tolerability of oral DMDs was better than other DMD treatments in an MS center population. ${ }^{48}$ A statistically significantly higher proportion of patients receiving self-injectable or intravenous DMDs reported not missing any doses compared with patients receiving oral DMDs. Fifty-five percent of patients receiving oral DMDs $(\mathrm{n}=89)$ reported no missed doses, $70.8 \%$ of patients taking SC or intramuscular DMDs $(n=90)$ reported not missing any doses, and $93.3 \%$ of patients taking intravenous DMDs $(n=30)$ reported no missed doses. The third study presented is the one described in this article. ${ }^{49}$ The objective of this study was to compare adherence to DMDs between patients with MS newly initiating treatment with a self-injectable DMD versus an oral DMD using a large US administrative claims dataset.

\section{Methods \\ Data source}

This was a retrospective database study conducted using IMS Health Real World Data Adjudicated Claims - US data between July 1, 2010 and June 30, 2014. The IMS Real World Data Adjudicated Claims - US Database comprises commercial health plan information from managed care plans throughout the US, with adjudicated claims from more than 150 million unique enrollees since 2006. This anonymous, patient-centric, national managed care database includes all medical and pharmacy claims data for study patients, as well as demographic variables (age, sex, region of the US), eligibility by month, and the adjudicated payment for services. Ethics approval from an Institutional Review Board and informed consent were not required for this research database as per US Department of Health and Human Services Exemption 4 (E4). The research involved the study of existing data, and patients could not be identified directly or through identifiers linked to the subjects.

\section{Patient population}

Eligibility criteria consisted of patients aged 18-64 years with at least one medical claim with a diagnosis for MS (International Classification of Diseases, Ninth Revision, Clinical Modification code: 340.xx) and at least one prescription for either a self-injectable or an oral DMD after MS diagnosis. The date of the first DMD prescription was defined as the index date. Patients were required to have continuous eligibility for at least 12 months before and 
12 months after the index date (ie, eligible to receive health care benefits during the 24-month time period over which they were evaluated). As the goal was to examine patients new to therapy, any patient with a DMD 12 months prior to the index date was excluded.

Patients were divided into two treatment cohorts based on the index DMD route of administration: the self-injectable DMD cohort and the oral DMD cohort. Self-injectable and oral DMDs included in the study are listed in Table 1.

\section{DMD adherence, discontinuation, and switching} Primary measure: DMD adherence

"Adherence to medications" is the process by which patients take their medication as prescribed and is further divided into three quantifiable phases: "initiation", "implementation", and "discontinuation". ${ }^{51}$ Adherence was evaluated during the 12-month follow-up period using the medication possession ratio (ie, annual MPR), and results were stratified by the route of administration (ie, self-injectable or oral). The annual MPR was calculated by totaling the number of days supply between the first prescription claim and the last prescription claim issued during the 12-month follow-up period (ie, the numerator) and dividing by the total number of days in the 12-month follow-up period (ie, the denominator).

The calculation was restricted to ambulatory days (ie, days when the patient was not in the hospital). Adherence to the index DMD was defined as an MPR $\geq 0.8 .{ }^{52}$

\section{Secondary measures: DMD discontinuation and switching}

DMD discontinuation and switching were also evaluated during the 12-month follow-up period as follows:

Table I Self-injectable and oral DMDs

\begin{tabular}{lll}
\hline Type & Generic name & ${\text { Brand } \text { name }^{\mathbf{a}}}$ \\
\hline Self-injectable DMD & Interferon beta-la & Avonex $^{\circledR}$ \\
& Interferon beta-lb & Betaseron $^{\circledR}$ \\
& Glatiramer acetate & Copaxone $^{\circledR}$ \\
& Interferon beta-lb & Extavia $^{\circledR}$ \\
& Interferon beta-la & Rebif $^{\circledR}$ \\
Oral DMD & Teriflunomide & Aubagio $^{\circledR}$ \\
& Fingolimod & Gilenya $^{\circledR}$ \\
& Dimethyl fumarate & Tecfidera $^{\circledR}$ \\
\hline
\end{tabular}

Notes: ${ }^{2}$ Aubagio ${ }^{\circledR}$ (teriflunomide) is a registered trademark of Genzyme Corporation (Cambridge, MA, USA); Avonex ${ }^{\circledR}$ (interferon beta-la) is a registered trademark of Biogen (Cambridge, MA, USA); Betaseron ${ }^{\circledR}$ (interferon beta-lb) is a registered trademark of Bayer (Whippany, NJ, USA); Copaxone ${ }^{\circledast}$ (glatiramer acetate injection) is a registered trademark of Teva Pharmaceutical Industries Ltd. (Overland Park, KS, USA); Extavia ${ }^{\circledR}$ (interferon beta-lb) is a registered trademark of Novartis AG (East Hanover, NJ, USA); Gilenya ${ }^{\circledR}$ (fingolimod) is a registered trademark of Novartis AG (Stein, Switzerland); Rebif ${ }^{\circledast}$ (interferon beta-la) is a registered trademark of EMD Serono, Inc. (Rockland, MA, USA; a business of Merck KGaA, Darmstadt, Germany); Tecfidera ${ }^{\circledR}$ (dimethyl fumarate) is a registered trademark of Biogen.

Abbreviation: DMD, disease-modifying drug.
- Discontinuation was defined as the absence of the index DMD for a 90-day period during follow-up, without evidence of another DMD during that time.

- Switching was defined as the presence of any other (nonindex) DMD during a 90-day period without the index DMD during follow-up.

\section{Descriptive/univariate analyses}

Baseline demographic and clinical characteristics were compared between index DMD cohorts, and included age, Charlson Comorbidity Index (CCI) score, and select common MS comorbidities based on a recent review of the published literature regarding comorbidities in patients with $\mathrm{MS}^{53}$ (ie, anxiety, arthritis [osteoarthritis or rheumatoid arthritis], depression, diabetes [type I and type II], gastrointestinal disorders [constipation, diarrhea, dysphagia, gastroesophageal reflux disease, and irritable bowel syndrome], hypertension, and thyroid disease). All measures concerning DMD adherence, discontinuation, and switching were evaluated for patients in both cohorts. Patients without valid "days of supply" values (ie, missing or $<0$ ) on relevant prescriptions were excluded from analyses related to adherence, discontinuation, and switching. Statistical testing of differences between cohorts was evaluated with Fisher's exact and Wilcoxon rank sum tests for binary/categorical and continuous measures, respectively. A $P$-value of $<0.05$ was used to determine statistical significance.

\section{Multivariable analysis}

Logistic regression was used to evaluate the likelihood of adherence (MPR $\geq 0.8$ ) to the index DMD type (selfinjectable or oral). Covariates included patient baseline characteristics (eg, age, sex, comorbidities) and index DMD type. Analyses were conducted using R version 3.2.1 software (The R Foundation, Vienna, Austria). ${ }^{54}$

\section{Results Patient selection}

A total of 7,207 patients with MS newly initiating a selfinjectable DMD and 1,175 patients with MS newly initiating an oral DMD met the eligibility criteria (Figure 1).

\section{Baseline characteristics}

Patient baseline characteristics for both index DMD cohorts, including age ranges, CCI score, and select common MS comorbidities, are shown in Table 2.

Patients in the self-injectable DMD cohort were younger compared with those in the oral DMD cohort (43.0 vs 44.9 years; $P<0.0001)$. Mean CCI score was higher among 


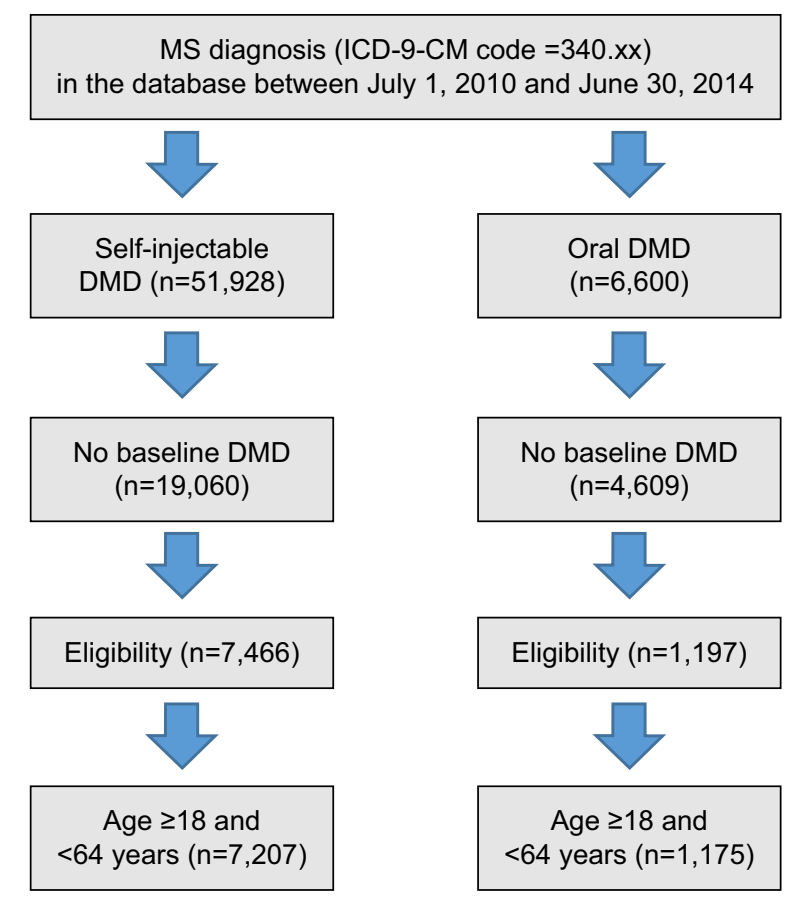

Figure I Patient selection flowchart.

Abbreviations: DMD, disease-modifying drug; ICD-9-CM, International Classification of Diseases, Ninth Revision, Clinical Modification; MS, multiple sclerosis.

Table 2 Baseline demographic and clinical characteristics of patients with MS newly initiating a DMD

\begin{tabular}{|c|c|c|c|}
\hline Characteristics & $\begin{array}{l}\text { Self-injectable } \\
\text { DMD }\end{array}$ & $\begin{array}{l}\text { Oral } \\
\text { DMD }\end{array}$ & $P$-value \\
\hline $\mathrm{n}$ & 7,207 & $\mathrm{I}, 175$ & - \\
\hline Age, years, mean & 43.0 & 44.9 & $<0.0001$ \\
\hline Age group, years, n (\%) & & & $<0.0001$ \\
\hline $18-34$ & I,654 (22.9) & $187(15.9)$ & \\
\hline $35-44$ & $2,217(30.8)$ & $352(30.0)$ & \\
\hline $45-54$ & $2,201(30.5)$ & $428(36.4)$ & \\
\hline $55-64$ & $\mathrm{I}, 135(\mathrm{I} 5.7)$ & $208(17.7)$ & \\
\hline Female, n (\%) & $5,531(76.7)$ & $895(76.2)$ & 0.6825 \\
\hline Region, n (\%) & & & $0.785 I$ \\
\hline Northeast & $2,240(3 I . I)$ & $368(3 \mid .3)$ & \\
\hline Midwest & $2,409(33.4)$ & $376(32.0)$ & \\
\hline South & $2,151(29.8)$ & $362(30.8)$ & \\
\hline West & $407(5.6)$ & $69(5.9)$ & \\
\hline $\mathrm{CCl}$ score, mean & 0.55 & 0.48 & 0.0242 \\
\hline \multicolumn{4}{|l|}{ Select comorbidities, n (\%) } \\
\hline Anxiety & $940(13.0)$ & $149(12.7)$ & 0.7789 \\
\hline Arthritis (RA/OA) & $556(7.7)$ & $87(7.4)$ & 0.7676 \\
\hline Depression & $410(5.7)$ & $78(6.6)$ & 0.2017 \\
\hline Diabetes & $568(7.9)$ & $80(6.8)$ & 0.2162 \\
\hline Gastrointestinal disease $\mathrm{a}^{\mathrm{a}}$ & $\mathrm{I}, 227(17.0)$ & $234(19.9)$ & 0.0180 \\
\hline Hypertension & I,715 (23.8) & $255(2 \mid .7)$ & 0.1193 \\
\hline Thyroid disease & I,II7 (I5.5) & $180(15.3)$ & 0.8962 \\
\hline
\end{tabular}

Notes: Due to rounding, percentages do not always equal 100\%. alncludes constipation, diarrhea, dysphagia, gastroesophageal reflux disease, and irritable bowel syndrome.

Abbreviations: $\mathrm{CCl}$, Charlson Comorbidity Index; DMD, disease-modifying drug; MS, multiple sclerosis; OA, osteoarthritis; RA, rheumatoid arthritis. patients on self-injectable DMDs compared with those on oral DMDs ( 0.55 vs $0.48 ; P=0.0242)$. The most common comorbidity at baseline in both cohorts was hypertension (21.7\%-23.8\% of patients), while the proportion with gastrointestinal disease was lower among patients on selfinjectable DMDs compared with those on oral DMDs $(17.0 \%$ vs $19.9 \% ; P=0.0180$ ).

\section{DMD adherence, discontinuation, and switching}

In unadjusted analyses, mean MPR was higher in the selfinjectable DMD cohort versus the oral DMD cohort ( 0.69 vs 0.68 , respectively; $P=0.0002$ ) (Table 3 ), while the proportion of patients adherent to therapy (MPR $\geq 0.8$ ) did not differ significantly between the cohorts $(54.1 \%$ vs $53.0 \%$, respectively; $P=0.5075$ ) (Table 3).

No significant differences between the self-injectable and oral DMD cohorts were observed in the proportion of patients discontinuing ( $26.6 \%$ vs $28.2 \%$, respectively; $P=0.2710$ ), the time to discontinuation (mean number of days: 118.0 vs 113.7, respectively; $P=0.1341$ ), or the time to switch (mean number of days: 163.1 vs 153.1 , respectively; $P=0.2519$ ). A higher proportion of patients in the self-injectable DMD cohort switched to another DMD compared with the oral DMD cohort ( $9.9 \%$ vs $6.6 \%$, respectively; $P=0.0003$ ). In both cohorts, the majority of patients who switched to another DMD switched to a self-injectable therapy (Table 3).

Table 3 Adherence and discontinuation characteristics among patients with MS newly initiating a DMD: unadjusted bivariate analyses

\begin{tabular}{|c|c|c|c|}
\hline Characteristics & $\begin{array}{l}\text { Self-injectable } \\
\text { DMD }\end{array}$ & $\begin{array}{l}\text { Oral } \\
\text { DMD }\end{array}$ & $P$-value \\
\hline n & 7,207 & I, 175 & - \\
\hline \multicolumn{4}{|l|}{ Adherence } \\
\hline Mean MPR (SD) & $0.69(0.30)$ & $0.68(0.30)$ & 0.0002 \\
\hline Adherent to therapy, ${ }^{a} \mathrm{n}(\%)$ & 3,898 (54.I) & $623(53.0)$ & 0.5075 \\
\hline $\begin{array}{l}\text { Remained on index therapy, } \\
n(\%)\end{array}$ & $4,574(63.5)$ & $766(65.2)$ & 0.2660 \\
\hline $\begin{array}{l}\text { Discontinued index therapy, } \\
\mathrm{n}(\%)\end{array}$ & $1,917(26.6)$ & $33 \mid(28.2)$ & 0.2710 \\
\hline $\begin{array}{l}\text { Mean time to } \\
\text { discontinuation, days (SD) }\end{array}$ & II $8.0(79.3)$ & II $3.7(86.2)$ & 0.1341 \\
\hline Switched to other DMD, ${ }^{c} \mathrm{n}(\%)$ & $716(9.9)$ & $78(6.6)$ & 0.0003 \\
\hline $\begin{array}{l}\text { Switched to self-injectable, } \\
\mathrm{n}(\%)\end{array}$ & $337(47.1)$ & $46(59.0)$ & \\
\hline Switched to oral, n (\%) & $255(35.6)$ & $22(28.2)$ & \\
\hline Switched to other, n (\%) & $124(17.3)$ & $10(12.8)$ & \\
\hline Mean days to switch (SD) & I63.I (75.7) & I53.I (80.0) & 0.2519 \\
\hline
\end{tabular}

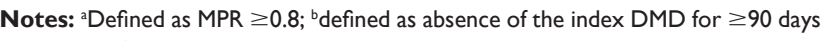
during the follow-up period without switching to another DMD during those 90 days; 'defined as switching from the index DMD to another DMD.

Abbreviations: DMD, disease-modifying drug; MPR, medication possession ratio; MS, multiple sclerosis; SD, standard deviation. 
Table 4 Multivariable analysis of potential predictors of adherence

\begin{tabular}{|c|c|c|c|c|}
\hline Covariate & $\begin{array}{l}\text { OR } \\
\text { estimate }\end{array}$ & $\begin{array}{l}\text { Lower } \\
95 \% \mathrm{Cl}\end{array}$ & $\begin{array}{l}\text { Upper } \\
95 \% \mathrm{Cl}\end{array}$ & $P$-value \\
\hline Male (vs female) & 1.203 & 1.085 & 1.335 & 0.0005 \\
\hline \multicolumn{5}{|l|}{ Age group, years (vs I8-34) } \\
\hline $35-44$ & 1.220 & 1.081 & 1.376 & 0.0013 \\
\hline $45-54$ & 1.331 & I. 178 & 1.505 & $<0.0001$ \\
\hline $55-64$ & 1.321 & 1.138 & 1.533 & 0.0003 \\
\hline \multicolumn{5}{|l|}{ Select comorbidities } \\
\hline \multicolumn{5}{|l|}{ (vs none) } \\
\hline Anxiety & 1.047 & 0.917 & 1.195 & 0.4995 \\
\hline Arthritis (RA/OA) & 0.909 & 0.770 & 1.073 & 0.2586 \\
\hline Depression & 0.618 & 0.511 & 0.747 & $<0.0001$ \\
\hline Diabetes & 0.906 & 0.767 & 1.072 & 0.2505 \\
\hline Gastrointestinal disease & 0.893 & 0.795 & 1.003 & 0.0572 \\
\hline Hypertension & 0.939 & $0.84 I$ & 1.049 & $0.266 I$ \\
\hline Thyroid disease & 0.947 & 0.838 & 1.069 & 0.3781 \\
\hline $\begin{array}{l}\text { Self-injectable DMD } \\
\text { (vs oral DMD) }\end{array}$ & 1.062 & 0.937 & 1.202 & 0.3473 \\
\hline
\end{tabular}

Abbreviations: $\mathrm{Cl}$, confidence interval; $\mathrm{DMD}$, disease-modifying drug; $\mathrm{OA}$, osteoarthritis; OR, odds ratio; RA, rheumatoid arthritis.

\section{Multivariable analysis}

Factors predictive of DMD adherence in the multivariable analyses are shown in Table 4. The logistic regression analysis shows that, after controlling for covariates, index DMD type (self-injectable DMD vs oral DMD) was not a significant predictor of adherence (odds ratio [OR] 1.062; 95\% confidence interval [CI]: 0.937-1.202; $P=0.3473)$. Male sex (OR 1.203; 95\% CI: $1.085-1.335 ; P=0.0005$ ) and age groups older than 18-34 years (ORs 1.220-1.331; $P<0.01$ ) were associated with a higher likelihood of adherence. The presence of depression at baseline was associated with a lower likelihood of adherence (OR 0.618; 95\% CI: $0.511-0.747 ; P<0.0001)$.

\section{Discussion}

As the MS DMD treatment options have expanded to include oral therapies, it is important to understand whether the route of administration is associated with treatment adherence. In addition to the traditional factors of clinical efficacy, safety, and costs, differences in patient adherence to therapies in MS may be important in formulary decision making. ${ }^{8}$ This study evaluated the impact of route of administration of DMD on patient adherence, and compared adherence between patients with MS newly initiating a self-injectable DMD versus an oral DMD.

The study findings showed that, in unadjusted analyses, the mean MPR was statistically significantly higher in the self-injectable DMD cohort compared with the oral DMD cohort; however, the proportion of patients adherent to therapy was similar between the two cohorts. A statistically significantly higher proportion of patients in the self-injectable DMD cohort switched therapies. There was no statistically significant difference in discontinuation rates between the self-injectable and the oral DMD cohorts.

In analyses adjusted for patient baseline characteristics (eg, age, sex, comorbidities) and index DMD type, the latter was not a significant predictor of DMD adherence, thus indicating that treatment adherence in patients with MS is complex and may not be exclusively influenced by the route of administration. Male sex and age older than 18-34 years were significantly associated with a higher likelihood of adherence, whereas depression at baseline was associated with a lower likelihood of adherence. These results are consistent with previously published studies which showed that male sex, older age, and less depression were associated with improved adherence. , $, 9,17-47$ The adjusted analyses highlight the importance of consideration of covariates in nonrandomized analyses.

The finding that a statistically significantly higher proportion of patients in the self-injectable DMD cohort switched therapies could be due to the availability of oral DMDs. A recently published prospective, observational substudy of the MSBase registry by Warrender-Sparkes et al showed that, following the introduction of fingolimod, patients were more likely to discontinue treatments (hazard ratio $1.64, P<0.001)$ and switch to fingolimod $(42.3 \%$ of switches). ${ }^{47}$ It is important to note that the definition of discontinuation in the study by Warrender-Sparkes et al included patients who switched to another therapy, whereas the current study defined discontinuation as stopping therapy and not switching to another therapy ${ }^{47}$ There was no statistically significant difference in discontinuation rates between the self-injectable and the oral DMD cohorts in our study. Multivariable analyses would be helpful to explore these findings.

Lack of medication adherence remains a challenge among patients with MS. Maximizing adherence to MS therapies to improve a patient's ability to gain the full benefit from their treatment is an important therapeutic goal. Improvements in adherence have the potential to reduce patient and payer burden in terms of improved clinical outcomes and lower nonpharmacy medical resource utilization. ${ }^{8}$ It is important for the health care providers to identify and implement the strategies to overcome and monitor barriers to adherence in MS. These may include improved patient education and support programs, particularly those related to better informing patients about treatment benefits. ${ }^{8}$ 
As the disease course of MS is unpredictable, and the patient's attitudes and behavior patterns can change, encouraging adherence is a complex issue. ${ }^{55}$ A patient's support team needs to be aware of the potential factors affecting adherence and be sensitive to the patient's needs in order to support the patient with the goal of establishing and maintaining adherence. ${ }^{56}$ Interestingly, Lorefice et al found that caregivers believed that patients were more involved in choosing their therapy than the patients themselves did. ${ }^{57}$ The importance of adherence with DMDs should be discussed as part of patient-centered medical care and shared decision making. Health information technology and comparative effectiveness research, two major components of health reform, have the potential to play important roles in promoting adherence to medications and expanding research on adherence interventions. ${ }^{58}$

Limitations of this study should be considered when interpreting the study findings. The data were obtained for claims processing and payment, and not for research purposes.$^{59}$ Claims data are subject to possible coding errors and undercoding. ${ }^{59}$ Services may not be captured in the claims database because the particular service is not covered by the plan sponsor or the service is "carved out" and not captured in the dataset (eg, mental health). ${ }^{59}$ Data fields that are not required for reimbursement may be particularly unreliable. ${ }^{59}$

When using prescription claims data, a number of different medication adherence measures can be examined, including length of therapy, persistence, days covered, gaps, and MPRs. The MPR is one of the most widely used measures of adherence using retrospective data. ${ }^{52}$ The advantage of using the MPR as a measure of adherence is it provides a comprehensive estimate of the proportion of time that a patient had medication available during the observation period. However, the use of the MPR to evaluate adherence has been criticized by some researchers because it may overestimate the true rate of medication adherence..$^{52}$ The overestimation is most likely to occur when the patient receives early refills of the target medications, which may result in an "extra fill" during a defined measurement interval. ${ }^{52}$ Also, since the MPR is being calculated for a class of medications (ie, DMDs), a switch between DMDs during the interval, with an overlap of the new drug with the prior drug, will inflate the MPR. ${ }^{52}$

Annual MPR was utilized instead of a variable MPR (eg, denominator ending at the last treated day), which may impact results by underestimating adherence in either cohort. Although the analysis aimed to identify patients new to DMD therapy by requiring no DMD claim during the 12-month baseline period, it is possible that patients could have been treated with DMDs prior to baseline and discontinued for that period. Additionally, patients in the sample were not necessarily newly diagnosed patients with MS.

Adherence measures based on administrative prescription data can only capture medication availability. There are challenges associated with how to account for patients who change health plans or who are no longer in the database. Also, adjustment for baseline differences between treatment cohorts cannot ensure all confounders are accounted for. Our ability to control for differences in the treatment groups was limited to the variables available in the database. Finally, there is a lack of generalizability of data, given the inherent characteristics of claims databases and the use of an individual cohort. The patients included in the database received treatment in all regions of the US. However, care should be exercised when extrapolating these findings to other health care settings.

\section{Conclusion}

This real-world study of patients with MS demonstrated that after controlling for covariates, route of administration for DMD treatments (ie, self-injectable DMD or oral DMD) was not a significant predictor of adherence. Male sex and age older than 18-34 years were significantly associated with a higher likelihood of adherence, and depression at baseline was associated with a lower likelihood of adherence.

\section{Acknowledgments}

The authors thank Natalie Edwards of Health Services Consulting Corporation, Boxborough, MA, USA (supported by EMD Serono, Inc., Rockland, MA, USA [a business of Merck KGaA, Darmstadt, Germany]) for editorial assistance in drafting the manuscript, collating the comments of authors, and assembling tables and figures, and Caudex, New York, NY, USA (supported by EMD Serono, Inc., Rockland, MA, USA [a business of Merck KGaA, Darmstadt, Germany]) for editorial assistance with the manuscript.

Portions of the data in this manuscript were presented at:

- The 2015 National Association of Specialty Pharmacy (NASP) Annual Meeting \& Expo, September 29-October 1, 2015, National Harbor, MD, USA, as a poster with interim findings (the poster's abstract was published on NASP's website, abstract \#4).

- The 31st Congress of the European Committee for Treatment and Research in Multiple Sclerosis (ECTRIMS), October 7-10, 2015, Barcelona, Spain, as a poster with interim findings (the poster's abstract was published in Multiple Sclerosis Journal, abstract P1157). 


\section{Disclosure}

MM and JM are employees of Boston Health Economics, Inc. MF is a former employee of Boston Health Economics, Inc. Boston Health Economics, Inc., received funding from EMD Serono, Inc., Rockland, MA, USA (a business of Merck KGaA, Darmstadt, Germany) to conduct the analyses. ALP is an employee of EMD Serono, Inc., Rockland, MA, USA (a business of Merck KGaA, Darmstadt, Germany). The authors received no funding for their participation in the writing of the manuscript. The authors report no other conflicts of interest in this work.

\section{References}

1. National Multiple Sclerosis Society. Multiple Sclerosis FAQs. Available from: http://www.nationalmssociety.org/What-is-MS/MS-FAQ-s. Accessed March 18, 2016.

2. Sharac J, McCrone P, Sabes-Figuera R. Pharmacoeconomic considerations in the treatment of multiple sclerosis. Drugs. 2010;70(13): 1677-1691.

3. National Multiple Sclerosis Society. Understanding Multiple Sclerosis. Available from: http://calmain.nationalmssociety.org/site/PageNavigator/ CAL_Exercise_MS1_Treated. Accessed March 21, 2016.

4. National Multiple Sclerosis Society. Medications. Available from: http://www.nationalmssociety.org/Treating-MS/Medications. Accessed March 21, 2016.

5. Agashivala N, Wu N, Abouzaid S, et al. Compliance to fingolimod and other disease modifying treatments in multiple sclerosis patients, a retrospective cohort study. BMC Neurol. 2013;13:138.

6. Bergvall N, Petrilla AA, Karkare SU, et al. Persistence with and adherence to fingolimod compared with other disease-modifying therapies for the treatment of multiple sclerosis: a retrospective US claims database analysis. J Med Econ. 2014;17(10):696-707.

7. Brandes DW, Callender T, Lathi E, O’Leary S. A review of diseasemodifying therapies for MS: maximizing adherence and minimizing adverse events. Curr Med Res Opin. 2009;25(1):77-92.

8. Menzin J, Caon C, Nichols C, White LA, Friedman M, Pill MW. Narrative review of the literature on adherence to disease-modifying therapies among patients with multiple sclerosis. J Manag Care Pharm. 2013;19(1 Suppl A):S24-S40.

9. Devonshire V, Lapierre Y, Macdonell R, et al. The Global Adherence Project (GAP): a multicenter observational study on adherence to disease-modifying therapies in patients with relapsing-remitting multiple sclerosis. Eur J Neurol. 2010;18(1):69-77.

10. Steinberg SC, Faris RJ, Chang CF, Chan A, Tankersley MA. Impact of adherence to interferons in the treatment of multiple sclerosis: a nonexperimental, retrospective, cohort study. Clin Drug Investig. 2010; 30(2):89-100.

11. Tan H, Yu J, Tabby D, Devries A, Singer J. Clinical and economic impact of a specialty care management program among patients with multiple sclerosis: a cohort study. Mult Scler. 2010;16(8):956-963.

12. Tan H, Cai Q, Agarwal S, Stephenson JJ, Kamat S. Impact of adherence to disease-modifying therapies on clinical and economic outcomes among patients with multiple sclerosis. Adv Ther. 2011;28(1): $51-61$.

13. Varming AR, Hansen UM, Andresdottir G, Husted GR, Willaing I. Empowerment, motivation, and medical adherence (EMMA): the feasibility of a program for patient-centered consultations to support medication adherence and blood glucose control in adults with type 2 diabetes. Patient Prefer Adherence. 2015;9:1243-1253.

14. Caon C, Saunders C, Smrtka J, Baxter N, Shoemaker J. Injectable diseasemodifying therapy for relapsing-remitting multiple sclerosis: a review of adherence data. J Neurosci Nurs. 2010;42(5 Suppl):S5-S9.
15. Holland N, Wiesel P, Cavallo P, et al. Adherence to disease-modifying therapy in multiple sclerosis: Part I. Rehabil Nurs. 2001;26(5): $172-176$.

16. Treadaway K, Cutter G, Salter A, et al. Factors that influence adherence with disease-modifying therapy in MS. J Neurol. 2009;256(4): 568-576.

17. Berger BA, Hudmon KS, Liang H. Predicting treatment discontinuation among patients with multiple sclerosis: application of the transtheoretical model of change. J Am Pharm Assoc (2003). 2004;44(4): $445-454$.

18. Dor A, Lage MJ, Tarrants ML, Castelli-Haley J. Cost sharing, benefit design, and adherence: the case of multiple sclerosis. Adv Health Econ Health Serv Res. 2010;22:175-193.

19. Evans C, Tam J, Kingwell E, Oger J, Tremlett H. Long-term persistence with the immunomodulatory drugs for multiple sclerosis: a retrospective database study. Clin Ther. 2012;34(2):341-350.

20. Fraser C, Hadjimichael O, Vollmer T. Predictors of adherence to Copaxone therapy in individuals with relapsing-remitting multiple sclerosis. J Neurosci Nurs. 2001;33(5):231-239.

21. Fraser C. Predictors of adherence to glatiramer acetate therapy in individuals with self-reported progressive forms of multiple sclerosis. J Neurosci Nurs. 2003;35(3):163-170.

22. Fraser C, Morgante L, Hadjimichael O, Vollmer T. A prospective study of adherence to glatiramer acetate in individuals with multiple sclerosis. J Neurosci Nurs. 2004;36(3):120-129.

23. Gleason PP, Starner CI, Gunderson BW, Schafer JA, Sarran HS. Association of prescription abandonment with cost share for high-cost specialty pharmacy medications. J Manag Care Pharm. 2009;15(8):648-658.

24. Grytten N, Aarseth JH, Espeset K, et al. Stoppers and non-starters of disease-modifying treatment in multiple sclerosis. Acta Neurol Scand. 2013;127(2):133-140.

25. Halpern R, Agarwal S, Dembek C, Borton L, Lopez-Bresnahan M. Comparison of adherence and persistence among multiple sclerosis patients treated with disease-modifying therapies: a retrospective administrative claims analysis. Patient Prefer Adherence. 2011;5:73-84.

26. Jokubaitis VG, Spelman T, Lechner-Scott J, et al. The Australian Multiple Sclerosis (MS) immunotherapy study: a prospective, multicentre study of drug utilisation using the MSBase platform. PLoS One. 2013;8(3):e59694.

27. Kozma CM, Phillips AL, Meletiche DM. Use of an early diseasemodifying drug adherence measure to predict future adherence in patients with multiple sclerosis. J Manag Care Spec Pharm. 2014;20(8): 800-807.

28. Lugaresi A, Florio C, Brescia-Morra V, et al. Patient adherence to and tolerability of self-administered interferon beta-1a using an electronic autoinjection device: a multicentre, open-label, phase IV study. BMC Neurol. 2012;12:7.

29. Lulu S, Julian L, Shapiro E, Hudson K, Waubant E. Treatment adherence and transitioning youth in pediatric multiple sclerosis. Mult Scler Relat Disord. 2014;3(6):689-695.

30. Mohr DC, Boudewyn AC, Likosky W, Levine E, Goodkin DE. Injectable medication for the treatment of multiple sclerosis: the influence of self-efficacy expectations and injection anxiety on adherence and ability to self-inject. Ann Behav Med. 2001;23(2):125-132.

31. Pozzilli C, Schweikert B, Ecari U, Oentrich W. Supportive strategies to improve adherence to IFN beta-1b in Multiple Sclerosis - results of the BetaPlus observational cohort study. J Neurol Sci. 2011;307(1-2): $120-126$.

32. Reynolds MW, Stephen R, Seaman C, Rajagopalan K. Healthcare resource utilization following switch or discontinuation in multiple sclerosis patients on disease modifying drugs. J Med Econ. 2010;13(1):90-98.

33. Reynolds MW, Stephen R, Seaman C, Rajagopalan K. Persistence and adherence to disease modifying drugs among patients with multiple sclerosis. Curr Med Res Opin. 2010;26(3):663-674.

34. Rio J, Porcel J, Tellez N, et al. Factors related with treatment adherence to interferon beta and glatiramer acetate therapy in multiple sclerosis. Mult Scler. 2005;11(3):306-309. 
35. Tarrants M, Oleen-Burkey M, Castelli-Haley J, Lage MJ. The impact of comorbid depression on adherence to therapy for multiple sclerosis. Mult Scler Int. 2011;2011:271321.

36. Tremlett H, Vander Mei I, Pittas F, et al. Adherence to the immunomodulatory drugs for multiple sclerosis: contrasting factors affect stopping drug and missing doses. Pharmacoepidemiol Drug Saf. 2008;17(6): 565-576.

37. Turner AP, Kivlahan DR, Sloan AP, Haselkorn JK. Predicting ongoing adherence to disease modifying therapies in multiple sclerosis: utility of the health beliefs model. Mult Scler. 2007;13(9):1146-1152.

38. Turner AP, Williams RM, Sloan AP, Haselkorn JK. Injection anxiety remains a long-term barrier to medication adherence in multiple sclerosis. Rehabil Psychol. 2009;54(1):116-121.

39. Wicks P, Massagli M, Kulkarni A, Dastani H. Use of an online community to develop patient-reported outcome instruments: the Multiple Sclerosis Treatment Adherence Questionnaire (MS-TAQ). J Med Internet Res. 2011;13(1):e12.

40. Zecca C, Riccitelli GC, Calabrese P, et al. Treatment satisfaction, adherence and behavioral assessment in patients de-escalating from natalizumab to interferon beta. BMC Neurol. 2014;14:38.

41. Zwibel H, Pardo G, Smith S, Denney D, Oleen-Burkey M. A multicenter study of the predictors of adherence to self-injected glatiramer acetate for treatment of relapsing-remitting multiple sclerosis. J Neurol. 2011;258(3):402-411.

42. Evans C, Marrie RA, Zhu F, et al. Adherence and persistence to drug therapies for multiple sclerosis: a population-based study. Mult Scler Relat Disord. 2016;8:78-85.

43. Jongen PJ, Lemmens WA, Hupperts R, et al. Persistence and adherence in multiple sclerosis patients starting glatiramer acetate treatment: assessment of relationship with care received from multiple disciplines. Patient Prefer Adherence. 2016;10:909-917.

44. McKay KA, Tremlett H, Patten SB, et al. Determinants of nonadherence to disease-modifying therapies in multiple sclerosis: a crossCanada prospective study. Mult Scler. Epub 2016 Jun 29.

45. Paolicelli D, Cocco E, Di Lecce V, et al. Exploratory analysis of predictors of patient adherence to subcutaneous interferon beta-1a in multiple sclerosis: TRACER study. Expert Opin Drug Deliv. 2016;13(6): 799-805.

46. Saiz A, Mora S, Blanco J. Therapeutic compliance of first line diseasemodifying therapies in patients with multiple sclerosis. COMPLIANCE Study. Neurologia. 2015;30(4):214-222.

47. Warrender-Sparkes M, Spelman T, Izquierdo G, et al. The effect of oral immunomodulatory therapy on treatment uptake and persistence in multiple sclerosis. Mult Scler. 2016;22(4):520-532.
48. Dionne C, Ganguly R, Camac A, Chaves C. Do oral disease modifying agents (DMTs) improve adherence to MS treatment? A comparison of oral and injectable drugs. Presented at: Annual Meeting of the Consortium of Multiple Sclerosis Centers (CMSC); May 27-30; 2015; Indianapolis, IN, USA.

49. Munsell M, Locklear JC, Phillips AL, Frean M, Menzin J. An assessment of adherence among multiple sclerosis patients newly initiating treatment with a self-injectable versus oral disease-modifying drug. Presented at: Annual Meeting of the Consortium of Multiple Sclerosis Centers (CMSC); May 27-30; 2015; Indianapolis, IN, USA.

50. Shah S, Cooperman T, Kachur S. Evaluation of treatment adherence and persistence based on dosing frequency and route for self-administration of disease-modifying therapies in multiple sclerosis. Presented at: Academy of Managed Care Pharmacy (AMCP) 27th Annual Meeting; April 7-10; 2015; San Diego, CA, USA.

51. Vrijens B, De GS, Hughes DA, et al. A new taxonomy for describing and defining adherence to medications. Br J Clin Pharmacol. 2012; 73(5):691-705

52. Peterson AM, Nau DP, Cramer JA, Benner J, Gwadry-Sridhar F, Nichol M. A checklist for medication compliance and persistence studies using retrospective databases. Value Health. 2007;10(1):3-12.

53. Marrie RA, Cohen J, Stuve O, et al. A systematic review of the incidence and prevalence of comorbidity in multiple sclerosis: overview. Mult Scler. 2015;21(3):263-281.

54. The R Foundation. The R Project for Statistical Computing. Available from: https://www.r-project.org/. Accessed March 22, 2016.

55. Patti F. Optimizing the benefit of multiple sclerosis therapy: the importance of treatment adherence. Patient Prefer Adherence. 2010;4:1-9.

56. Glanz B, Holland C, Gauthier S, et al. Cognitive dysfunction in patients with clinically isolated syndromes or newly diagnosed multiple sclerosis. Mult Scler. 2007;13(8):1004-1010.

57. Lorefice L, Mura G, Coni G, et al. What do multiple sclerosis patients and their caregivers perceive as unmet needs? BMC Neurol. 2013; 13:177.

58. Gellad WF, Grenard J, McGlynn EA. A review of barriers to medication adherence: a framework for driving policy options. Available from: http://www.rand.org/content/dam/rand/pubs/technical_reports/2009/ RAND_TR765.pdf. Accessed March 16, 2016.

59. Motheral B, Brooks J, Clark MA, et al. A checklist for retrospective database studies - report of the ISPOR task force on retrospective databases. Value Health. 2003;6(2):90-97.
Patient Preference and Adherence

\section{Publish your work in this journal}

Patient Preference and Adherence is an international, peer-reviewed, open access journal that focuses on the growing importance of patient preference and adherence throughout the therapeutic continuum. Patient satisfaction, acceptability, quality of life, compliance, persistence and their role in developing new therapeutic modalities and compounds to optimize

\section{Dovepress}

clinical outcomes for existing disease states are major areas of interest for the journal. This journal has been accepted for indexing on PubMed Central. The manuscript management system is completely online and includes a very quick and fair peer-review system, which is all easy to use. Visit http://www dovepress.com/testimonials.php to read real quotes from published authors. 